\title{
Effect of Maternal Fluoxetine Administration on Uterine Blood Flow, Fetal Blood Gas Status, and Growth
}

\author{
JANNA LEIGH MORRISON, CALY CHIEN, KENNETH WAYNE RIGGS, NANCY GRUBER, AND \\ DAN RURAK \\ Department of Obstetrics and Gynaecology, British Columbia Research Institute for Children's \& \\ Women's Health, Vancouver, BC, Canada [J.L.M., N.G., D.R.]; Faculty of Pharmaceutical Sciences, \\ University of British Columbia, Vancouver, BC, Canada [C.C., K.W.R.]
}

\begin{abstract}
Clinical depression, diagnosed in $5-15 \%$ of women during pregnancy, increases the risk of negative pregnancy outcomes including an increased incidence of low birth weight newborns and preterm delivery. Fluoxetine, a selective serotonin reuptake inhibitor, is often prescribed to treat depression due to its efficacy, high margin of safety, and mild side effects. However, fluoxetine initially increases plasma serotonin concentration, and serotonin causes uterine vasoconstriction in sheep, which could result in fetal hypoxemia. To assess fetal fluoxetine effects, late-gestation pregnant sheep were surgically prepared for the measurement of blood gases, heart rate, blood pressure, and uterine artery blood flow $(n=29)$. Ewes received a 70-mg bolus i.v. infusion of fluoxetine over $2 \mathrm{~min}$ in $10 \mathrm{~mL}$ of sterile water followed by continuous infusion at a rate of $100 \mu \mathrm{g} / \mathrm{min}$ for $8 \mathrm{~d}$ $(n=14)$, or continuous infusion of sterile water $(n=15)$. Transient decreases in uterine artery blood flow, fetal $\mathrm{Po}_{2}$, and oxygen saturation were observed within the first 15 min after
\end{abstract}

\section{ABSTRACT}

fluoxetine exposure, which did not return to normal values by $24 \mathrm{~h}$. Fetal $\mathrm{pH}$ decreased and $\mathrm{PCO}_{2}$ increased over the first $4 \mathrm{~h}$ with a return to normal by $24 \mathrm{~h}$. However, there were no differences in uterine artery blood flow, blood gas status, or cardiovascular measures between the control and fluoxetine group over the rest of the 8-d infusion period. Thus, fluoxetine exposure during pregnancy has transient effects on fetal status that may be of developmental consequence if they occur repetitively. (Pediatr Res 51: 433-442, 2002)
FX, fluoxetine
NFX, norfluoxetine
SSRI, selective serotonin reuptake inhibitor
$\mathbf{U A B F}$, uterine artery blood flow
$\mathbf{s} \mathbf{H}_{\mathbf{2}} \mathbf{O}$, sterile water

\section{Abbreviations}

Depression occurs in 5-15\% of pregnant women, and an additional $10-15 \%$ of women experience postpartum depression (1). A study of general practitioner records in the United Kingdom from 1991 to 1996 showed that FX is the most prescribed SSRI (2). The SSRIs have fewer side effects than tricyclic antidepressants and monoamine oxidase inhibitors and thus are frequently prescribed during pregnancy (3). First trimester in utero exposure to FX does not result in teratogenic effects in humans $(4,5)$, whereas third trimester exposure has been reported to increase the incidence of preterm delivery,

Received March 13, 2001; accepted October 10, 2001.

Correspondence and reprint requests: Dr. Dan Rurak, BC Research Institute for Children's \& Women's Health, 950 West 28th Ave, Vancouver, BC, V5Z 4H4, Canada; e-mail: drurak@cw.bc.ca

Funding for this research was provided by the Canadian Institutes of Health Research (CIHR). D.R. is a recipient of an investigatorship award from the British Columbia Research Institute for Children's \& Women's Health. J.L.M. is a recipient of a CIHR studentship award. C.C. is a recipient of a PMAC/HRF-CIHR studentship award. admission to special care nursery, poor neonatal adaptation, and to decrease birth weight $(6,7)$. However, other studies have found no difference in birth weight, perinatal complications, or neurobehavioral development $(8,9)$.

Chronic FX treatment enhances serotonin neurotransmission by inhibiting serotonin reuptake by the serotonin transporter. In addition, presynaptic inhibitory $5 \mathrm{HT}_{1 \mathrm{~A}}$ and $5 \mathrm{HT}_{1 \mathrm{D} / 1 \mathrm{~B}}$ receptors are desensitized (9). Serotonin causes contraction of the human and sheep umbilical artery (10, 11). Injections of serotonin into the uterine artery in pregnant and nonpregnant sheep results in dose-dependent decreases in UABF ranging from $20 \%$ to $50 \%$ at doses of $1-10$ $\mu \mathrm{g}$ (12). Whether FX interacts directly with serotonin receptors or through changes in plasma levels of serotonin, a decrease in $\mathrm{UABF}$, either chronic or repeated, may be a mechanism for the possible negative effects of third trimester FX exposure. For this reason, we have measured UABF, blood gas status, and fetal growth during maternal FX infusion in late-gestation pregnant sheep. 


\section{METHODS}

Animals and surgical preparation. Twenty-nine time-bred Dorset/Suffolk cross, pregnant sheep were surgically prepared between 118 and $122 \mathrm{~d}$ gestation (term is approximately 145 d). The University of British Columbia Animal Care Committee approved experimental protocols and procedures performed on the sheep and these conformed to the guidelines of the Canadian Council on Animal Care. Surgical procedures have been described in detail previously (13). Briefly, anesthesia was induced by injection of $1 \mathrm{~g}$ pentothal via the jugular vein. After intubation, anesthesia was maintained with $1.5 \%$ isoflurane. The uterus was incised and the fetus exposed for the implantation of polyvinyl catheters (Tygon, Akron, OH, U.S.A.) in the trachea, both femoral arteries, a lateral tarsal vein, and the amniotic cavity. Electrodes of Teflon-coated stainless steel wire (Cooner, Chatsworth, CA, U.S.A.) were implanted for measurement of fetal behavioral state. In 11 animals, a Transonic blood flow transducer (Transonic Corp., Ithaca, NY, U.S.A.) was placed around the main uterine artery of the uterine horn containing the operated fetus for the continuous measurement of UABF. All catheters were flushed daily with approximately $2 \mathrm{~mL}$ of sterile $0.9 \%$ sodium chloride containing $12 \mathrm{U}$ heparin/mL to maintain their patency. Ampicillin $(500 \mathrm{mg}$ ) was administered into the amniotic cavity daily and intramuscularly to the ewe at surgery and for 3 postoperative days. Sheep were housed in holding pens with other sheep and had free access to food and water after surgery.

Experimental protocol. One preinfusion day preceded an 8 -d continuous infusion of $\mathrm{sH}_{2} \mathrm{O}(n=15)$ or $\mathrm{FX}(n=14)$. On infusion d 1, a bolus injection of $70 \mathrm{mg} \mathrm{FX}$ in $10 \mathrm{~mL} \mathrm{sH}_{2} \mathrm{O}$ or $10 \mathrm{~mL}$ of $\mathrm{sH}_{2} \mathrm{O}$ was given over 2 min into the maternal venous catheter followed by continuous infusion of $2.77 \mathrm{mg} / \mathrm{mL}$ FX or $\mathrm{sH}_{2} \mathrm{O}$ at a rate of $0.036 \mathrm{~mL} / \mathrm{min}$ (i.e. $100 \mu \mathrm{g} \mathrm{FX} / \mathrm{min}$ ) with a Harvard infusion pump (Harvard Apparatus, Millis, MA, U.S.A.). At $0700 \mathrm{~h}$ each day, maternal $(5 \mathrm{~mL})$ and fetal $(3 \mathrm{~mL})$ blood samples were collected for analysis of FX and blood gases. In addition, on the first day of the infusion, blood gas and FX samples were collected at $0(0700 \mathrm{~h}), 5,15$, and $30 \mathrm{~min}$ and $1,2,4,6$, and $12 \mathrm{~h}$ after the infusion began.

Blood gas analysis. Blood samples were analyzed for $\mathrm{pH}$, $\mathrm{P}_{\mathrm{CO}_{2}}$, and $\mathrm{PO}_{2}$ with an IL $1306 \mathrm{pH} /$ blood gas analyzer (Allied Instrumentation Laboratory, Milan, Italy) and temperature corrected to $39.5^{\circ} \mathrm{C}$ for fetal samples and $39^{\circ} \mathrm{C}$ for maternal samples. $\mathrm{Hb}$ and oxygen saturation were measured with an OSM-2 Hemoximeter (Radiometer, Copenhagen, Denmark). Glucose and lactate were determined with a glucose/lactate 2306 STAT plus analyzer (YSI Inc., Yellow Springs, OH, U.S.A.).

Physiologic monitoring. Maternal and fetal arterial pressure and heart rate were continuously recorded using a TA-4000 Gould (Gould Instrument Systems, Valley View, OH, U.S.A.) or a Grass K2G (Astro-Med, Montreal, QC, Canada) chart recorder that produced a record at a rate of 2.5 and $3 \mathrm{~mm} / \mathrm{min}$, respectively. UABF was measured using a Transonic transittime flow transducer and also recorded on the chart recorder. A PCL-718 data acquisition card (Advantech, Wilmington, MA, U.S.A.) converted the analogue data processed by the chart recorders to digital data that was processed and stored using Labtech software (Labtech, Wilmington, MA, U.S.A.).

Assessment of fetal and postnatal growth. Fetal head (anterior to the ears) and abdominal (anterior to the umbilical cord) circumference were measured at time of surgery and at birth. Lambs were weighed immediately after birth and towel drying, and between 0900 and $1000 \mathrm{~h}$ each day postnatally. Ewes and lambs were monitored after birth to ensure the lambs received colostrum and were able to suckle. If required because of multiple gestation or maternal udder problems, lambs were supplemented with commercial lamb milk formula.

Measurement of fluoxetine concentrations. A rapid, sensitive, and selective chiral assay for FX and NFX enantiomers using gas chromatography mass spectrometry with selective ion monitoring developed in our laboratory was used for FX and NFX analysis in plasma (14). Plasma values are shown for the six animals for whom maternal and fetal blood samples were collected at all time points in the protocol from $0700 \mathrm{~h}$ on the preinfusion day to $72 \mathrm{~h}$ after FX infusion ceased.

Statistical analysis. Blood gas, cardiovascular, and UABF data were analyzed using repeated measures ANOVA followed by post hoc Fishers $t$ tests to determine the effect of both time and treatment on changes in measurements from preinfusion values during the first $24 \mathrm{~h}$ after FX infusion and changes from the preinfusion day on each infusion day using NCSS (Kaysville, UT, U.S.A.). Birth weight and gestational age data were analyzed using unpaired $t$ tests. Results are presented as means \pm SEM. Due to the length of the protocol, all parameters were not collected from all animals at all time points.

\section{RESULTS}

Pregnancy outcome. Gestational age at delivery did not differ between the control (CON) $(142.5 \pm 1.6 \mathrm{~d})$ and FX (FX) $(142.4 \pm 1.5 \mathrm{~d})$ groups as shown in Table 1 . The birth weights of operated animals were not significantly different between the two groups (CON, $3662.8 \pm 334.2 \mathrm{~g}$; FX, $3481.4 \pm 218.8$ g). There was no significant difference in the percentage of live births between CON, $67 \%$, and FX, 64\%. Circumference of the fetal head (surgery: $22.5 \pm 0.6 \mathrm{~cm}, \mathrm{CON} ; 23.0 \pm 0.5 \mathrm{~cm}, \mathrm{FX}$; birth: $24.9 \pm 0.8 \mathrm{~cm}, \mathrm{CON} ; 25.2 \pm 0.6 \mathrm{~cm}, \mathrm{FX}$ ) and abdomen (surgery: $25.1 \pm 0.9 \mathrm{~cm}, \mathrm{CON} ; 26.5 \pm 0.9 \mathrm{~cm}, \mathrm{FX}$; birth: 34.6 $\pm 2.2 \mathrm{~cm}, \mathrm{CON} ; 34.5 \pm 1.1 \mathrm{~cm}, \mathrm{FX})$ and the ratios of head to abdominal circumference (surgery: $0.88 \pm 0.04, \mathrm{CON} ; 0.87 \pm$ 0.03 , FX; birth: $0.76 \pm 0.06$, CON; $0.73 \pm 0.02, \mathrm{FX})$ and body weight to head circumference (surgery: $170 \pm 29, \mathrm{CON} ; 154$ \pm 12 , FX; birth: $151 \pm 20$, CON; $140 \pm 10$, FX) were not significantly different between CON and FX at surgery or birth. This suggests that FX did not elicit fetal growth restriction. However, postnatal growth was significantly different between the CON and FX lambs and their siblings (Fig. 1), with decreased weight gain in the latter group on postnatal d 2 and increased weight gain on $\mathrm{d} 5$.

Plasma fluoxetine levels. On infusion d 1 (Fig. 2), FX levels in both the ewe and fetus peaked at $5 \mathrm{~min}$ after the bolus infusion $(173.3 \pm 31.4 \mathrm{ng} / \mathrm{mL}$ in the ewe and $26.8 \pm 3.9$ $\mathrm{ng} / \mathrm{mL}$ in the fetus) and decreased during the first $6 \mathrm{~h}(46.9 \pm$ $10.4 \mathrm{ng} / \mathrm{mL}$ in the ewe and $17.4 \pm 1.7 \mathrm{ng} / \mathrm{mL}$ in the fetus). 
Table 1. Gestational age (GA) at birth and birth weights of fetuses exposed to an 8-d infusion of sterile water (n $=15)$ or FX (n $=12)$ during late gestation.

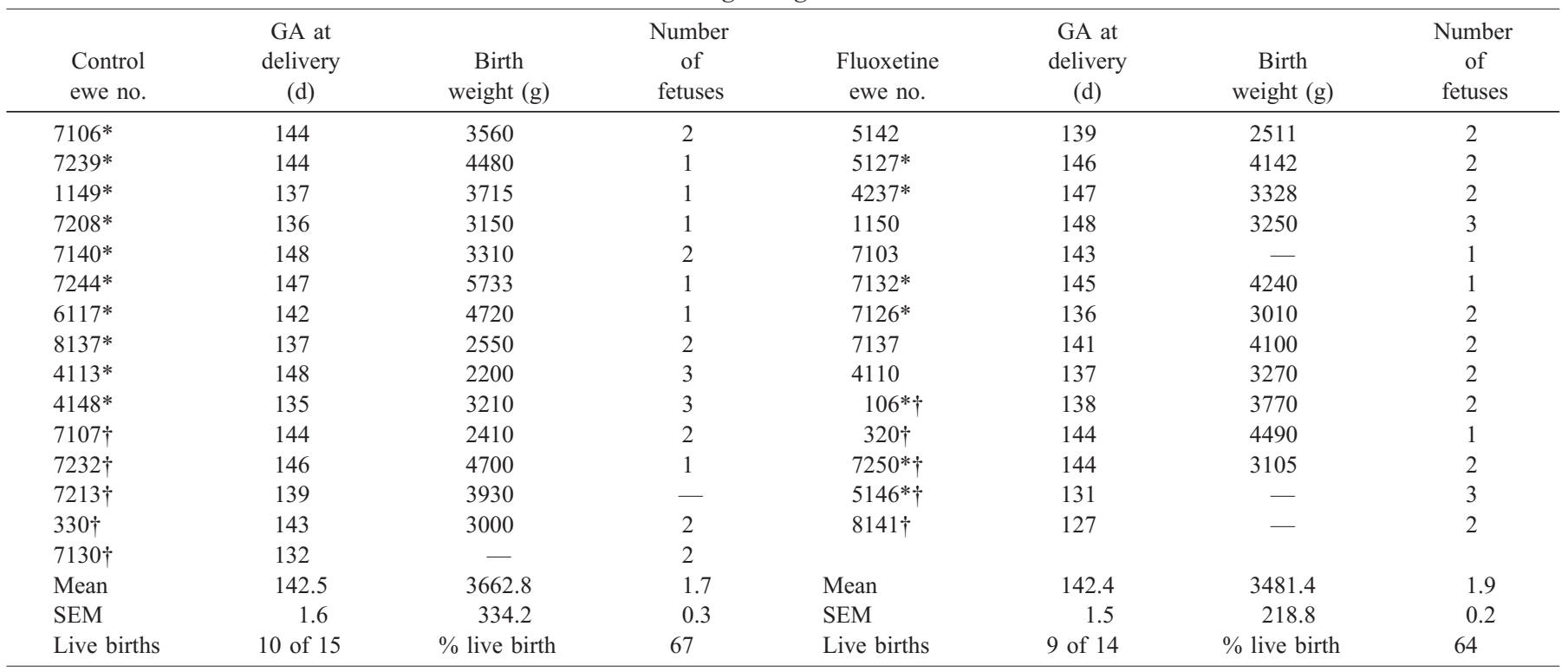

Mean birth weight and gestational age applies only to live born fetuses. No significant differences were observed in GA, birth weight, or number of fetuses.

* Indicates surviving operated and unoperated fetuses followed postnatally.

$\dagger$ Indicates fetuses that were born dead. Not included in mean values. Ewe 7213 died 1-4 d before delivery; 330 died between 0 and $9 \mathrm{~d}$ before delivery; 7130 died on Infusion d 6 and delivered 2 d later; 7107 had difficult labor; 7232 died 0-10 d before delivery; 5146 died 2 d before delivery on infusion d 3; 7250 died $3 \mathrm{~d}$ before delivery; 1150 refused to stand so protocol ended on infusion d 6 and returned to farm for delivery; 7103 born alive, birth weight unknown; 106 died just prior to delivery on infusion $\mathrm{d} 8$, twin survived; 320 fetus died on infusion $\mathrm{d} 7$ and delivered; 8141 died on infusion $\mathrm{d} 5$ and delivered the following day.

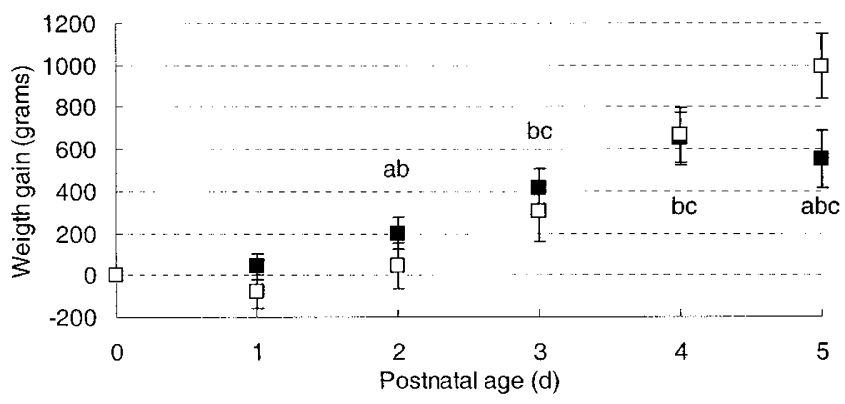

Figure 1. Postnatal weight gain in operated + sibling fetuses exposed prenatally to 8-d maternal i.v. infusion of $\mathrm{sH}_{2} \mathrm{O}$ (closed squares, $n=14$ ) or $\mathrm{FX}$ (open squares, $n=7$ ). (a) Significant difference between control and FX groups $(p<0.05)$; significant difference $(p<0.05)$ from day of birth in control (b) and FX group (c).

Plasma concentrations of FX's active metabolite, NFX, increased over the initial 6 -h period from $4.5 \pm 2.1 \mathrm{ng} / \mathrm{mL}$ to $25.3 \pm 3.4 \mathrm{ng} / \mathrm{mL}$ in the ewe and 0 to $8 \pm 1.2 \mathrm{ng} / \mathrm{mL}$ in the fetus. Maternal and fetal FX levels progressively increased throughout the 8-d infusion, peaking at $166.5 \pm 45 \mathrm{ng} / \mathrm{mL}$ on infusion $\mathrm{d} 7$ in the ewe and at $58.9 \pm 14.9 \mathrm{ng} / \mathrm{mL}$ on infusion d 8 in the fetus. Maternal and fetal plasma NFX levels also increased progressively during the infusion period. Fetal FX plasma levels were $37.1 \pm 0.0 \%$ of maternal levels from $6 \mathrm{~h}$ after the infusion began until the infusion ended.

Acute physiologic changes during fluoxetine infusion. Maternal and fetal blood gas and $\mathrm{pH}$ values during the first $24 \mathrm{~h}$ of $\mathrm{sH}_{2} \mathrm{O}$ or $\mathrm{FX}$ infusion are illustrated in Figures 3 and 4. In both groups, maternal arterial $\mathrm{Po}_{2}$ increased slightly during the

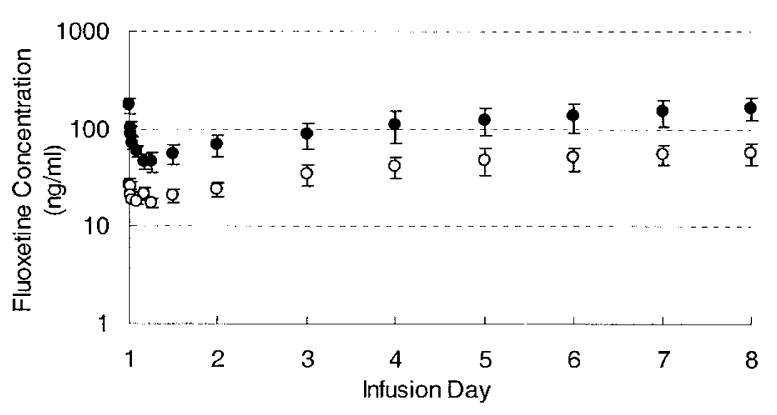

B

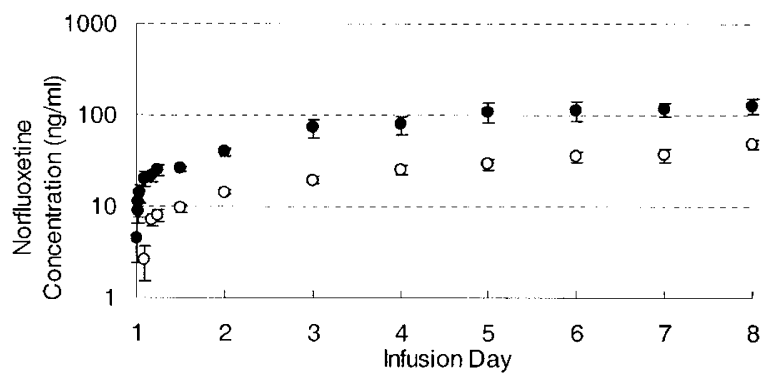

Figure 2. Maternal (closed circles, $n=6$ ) and fetal (open circles, $n=6$ ) FX $(A)$ and NFX $(B)$ arterial plasma concentrations at 5, 15, and 30 mins and 1,2, 4,6 , and $12 \mathrm{~h}$ after maternal $\mathrm{FX}$ administration as well as at $0700 \mathrm{~h}$ on each day of the 8-d infusion.

first 30 min of the infusion period, and in $\mathrm{CON}$, there was a small, but statistically significant increase in $\mathrm{pH}$ at $12 \mathrm{~h}$. No other significant maternal changes were observed. Compared with the preinfusion values, fetal $\mathrm{pH}, \mathrm{Po}_{2}$, and oxygen saturation decreased in $\mathrm{FX}$, whereas $\mathrm{PCO}_{2}$ increased $(p<0.05)$. Fetal $\mathrm{Po}_{2}$ fell $5.5 \pm 0.8 \mathrm{~mm} \mathrm{Hg}$ in the first $5 \mathrm{~min}$ of $\mathrm{FX}$ infusion from 

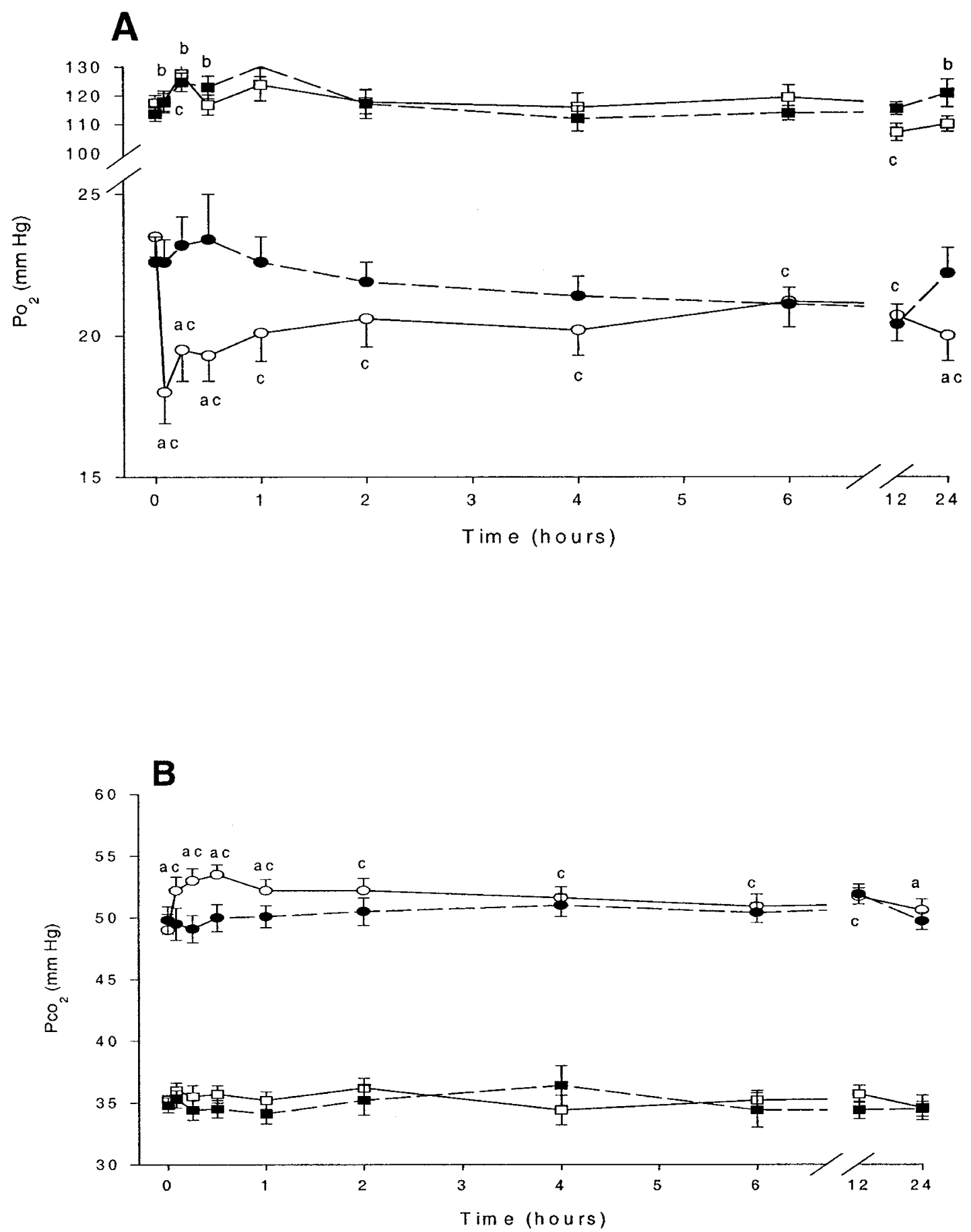

Figure 3. Maternal (squares) and fetal (circles) $\mathrm{Po}_{2}(A)$ and $\mathrm{PCO}_{2}(B)$ during the first 24 h of maternal i.v. $\mathrm{sH}{ }_{2} \mathrm{O}($ closed symbols, $n=14)$ or $\mathrm{FX}($ open symbols, $n=13$ ) infusion. (a) Significant difference between control and FX groups $(p<0.05)$; significant difference $(p<0.05)$ from preinfusion day in control $(b)$ and FX group $(c)$.

$23.5 \pm 0.7$ to $18.0 \pm 1.1 \mathrm{~mm} \mathrm{Hg}$. $\mathrm{Po}_{2}$ returned toward the preinfusion value but remained slightly but significantly decreased for the whole of the first day. There were similar changes in fetal $\mathrm{O}_{2}$ saturation (Fig. 4), with an initial decrease from $60.3 \pm 5.3$ to $41.9 \pm 8.5 \%$ at $5 \mathrm{~min}$ postinjection. The $\mathrm{pH}$ decrease was not associated with any change in base excess, which was $0.55 \pm 0.68 \mathrm{mEq} / \mathrm{L}$ before $\mathrm{FX}$ administration and $0.68 \pm 0.33 \mathrm{mEq} / \mathrm{L}$ at $30 \mathrm{~min}$, the time of the maximum fall in
$\mathrm{pH}$. In the CON group, fetal $\mathrm{Hb}$ concentration decreased from $10.7 \pm 0.4$ to $10.0 \pm 0.5 \mathrm{~g} / \mathrm{dL}$ at $5 \mathrm{~min}$ and remained at $10.3-10.8 \mathrm{~g} / \mathrm{dL}$ for the rest of the first day. Hb concentration in the FX fetuses $(10.0 \pm 0.5 \mathrm{~g} / \mathrm{dL})$ was not significantly altered. Figure 5 illustrates the changes in maternal and fetal glucose and lactate concentration during the first $24 \mathrm{~h}$. In both groups, the changes in maternal and fetal glucose concentration were parallel and the levels increased significantly after the feeding 

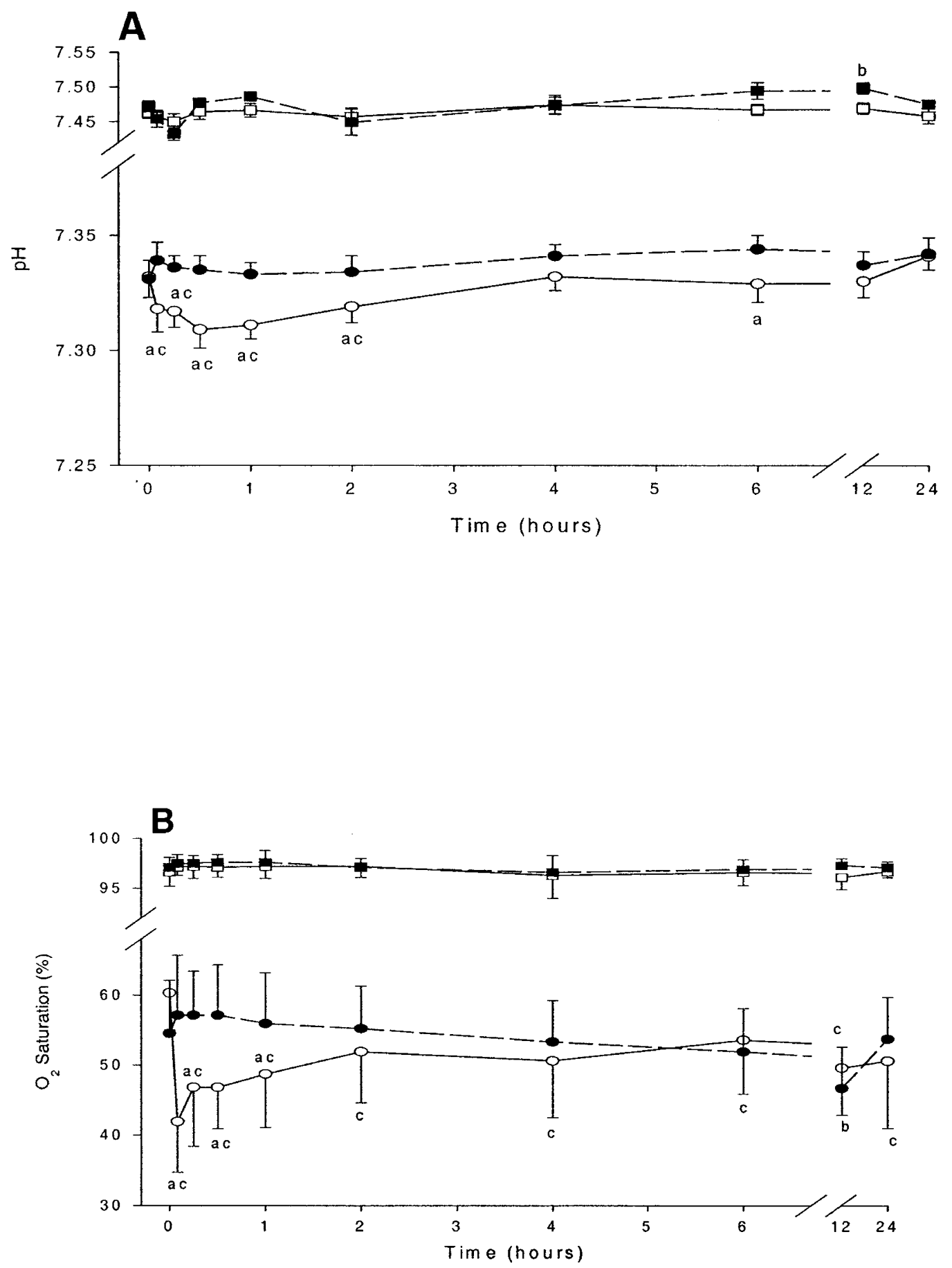

Figure 4. Maternal (squares) and fetal (circles) arterial $\mathrm{pH}(A)$ and oxygen saturation $(B)$ during the first $24 \mathrm{~h}$ of maternal $\mathrm{sH}_{2} \mathrm{O}($ closed symbols, $n=14)$ or FX infusion (open symbols, $n=13$ ). (a) Significant difference between control and FX groups $(p<0.05)$; significant difference $(p<0.05)$ from preinfusion day in control (b) and FX group (c).

of the animals between 1 and $2 \mathrm{~h}$. Maternal and fetal lactate concentrations increased in both groups, along with the rise in glucose. In addition, in the FX-exposed fetuses, there was a greater rise in the first hour of the infusion and the levels remained elevated above the preinfusion value for the remainder of the day.

Figure 6 illustrates the changes in maternal and fetal arterial pressure and heart rate during the first $24 \mathrm{~h}$ of the experiment. In FX, both fetal (46 $\pm 3 \mathrm{~mm} \mathrm{Hg}$ at $0 \mathrm{~h})$ and maternal (92 \pm
$3 \mathrm{~mm} \mathrm{Hg}$ at $0 \mathrm{~h}$ ) arterial pressure were higher than the values in the CON group (fetal, $45 \pm 1 \mathrm{~mm} \mathrm{Hg}$; maternal, $77 \pm 6 \mathrm{~mm}$ $\mathrm{Hg}$ at $0 \mathrm{~h}$ ) for the entire $24 \mathrm{~h}$, and for the ewe the differences between the groups were statistically significant at 4 and $6 \mathrm{~h}$. There were, however, no consistent changes in either maternal or fetal heart rate and blood pressure with time. Maternal heart rate $(\mathrm{CON}, 84 \pm 8 \mathrm{bpm}$; FX, $94 \pm 5 \mathrm{bpm}$ at $0 \mathrm{~h}$ ) was not significantly altered in either group. With FX, fetal heart rate increased significantly from $162 \pm 6 \mathrm{bpm}$ preinfusion to $188 \pm$ 

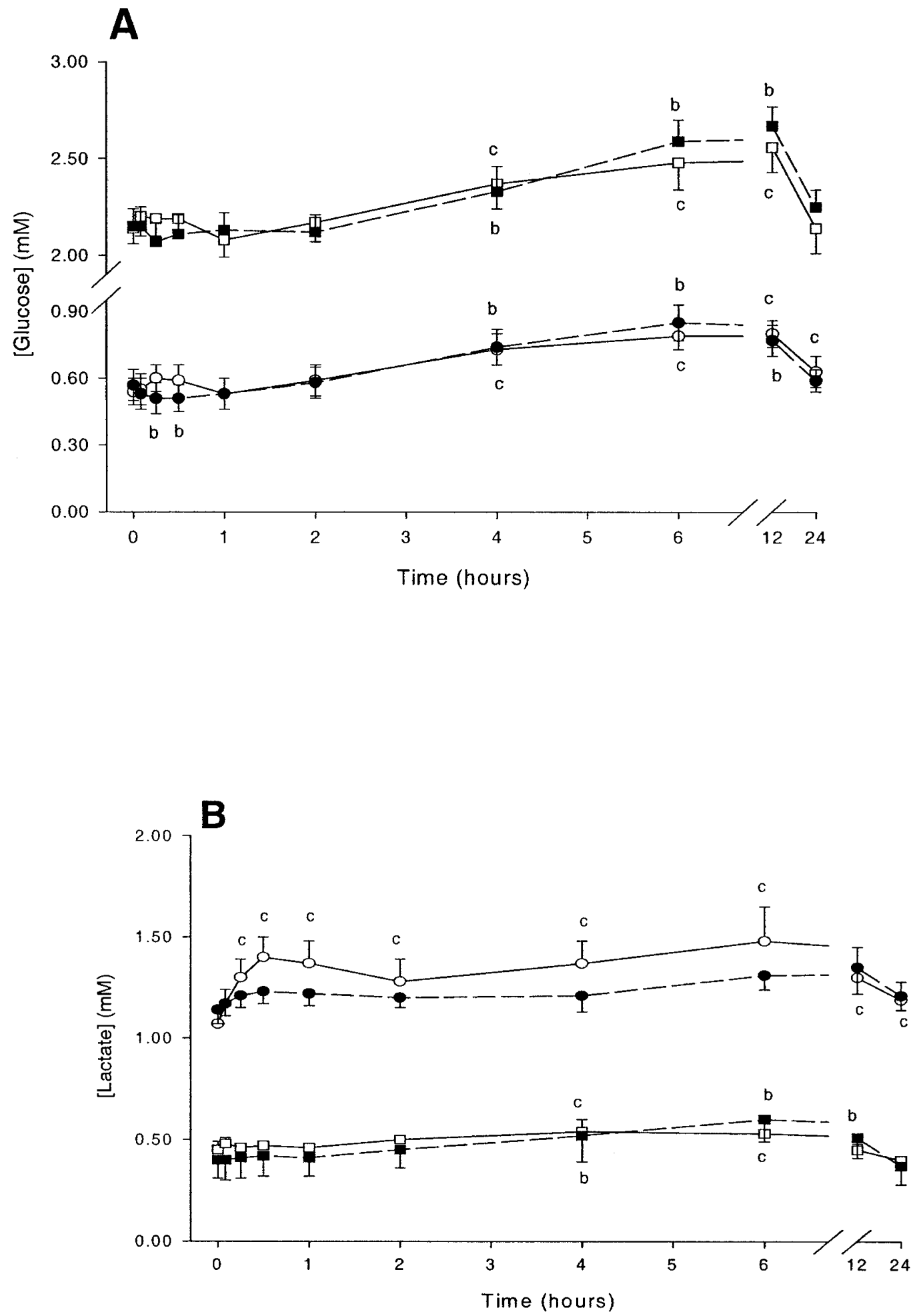

Figure 5. Maternal (squares) and fetal (circles) arterial glucose $(A)$ and lactate $(B)$ levels during the first $24 \mathrm{~h}$ of maternal $\mathrm{sH}_{2} \mathrm{O}($ closed symbols, $n=14)$ or FX (open symbols, $n=13$ ) infusion. Significant difference $(p<0.05)$ from preinfusion day in control $(b)$ and FX group $(c)$.

$7 \mathrm{bpm}$ at $1 \mathrm{~h}$ and remained elevated at 2 and $4 \mathrm{~h}$. In comparison with CON (167 $\pm 5 \mathrm{bpm}$ at $0 \mathrm{~h})$, fetal heart rate in FX fetuses was higher at every sampling point on the first day.

Absolute UABF decreased from $489 \pm 26 \mathrm{~mL} / \mathrm{min}$ preinfusion to $378 \pm 27 \mathrm{~mL} / \mathrm{min}$ at $5 \mathrm{~min}$ after FX infusion began with a return to $465 \pm 26 \mathrm{~mL} / \mathrm{min}$ by $1 \mathrm{~h}$ (Fig. $7 A$ ). This represents a fall to $74 \pm 6 \%$ of the preinfusion value at $5 \mathrm{~min}$ and $77 \pm 6 \%$ at 15 min with a return to preinfusion values by $1 \mathrm{~h}(p<0.05)$. No significant changes in UABF were observed in CON.

Daily physiologic changes with fluoxetine infusion. Blood gas status was monitored at $0700 \mathrm{~h}$ daily with the preinfusion day and infusion $\mathrm{d} 1$ samples being preinfusion samples. No changes in maternal blood gas status were observed with FX 

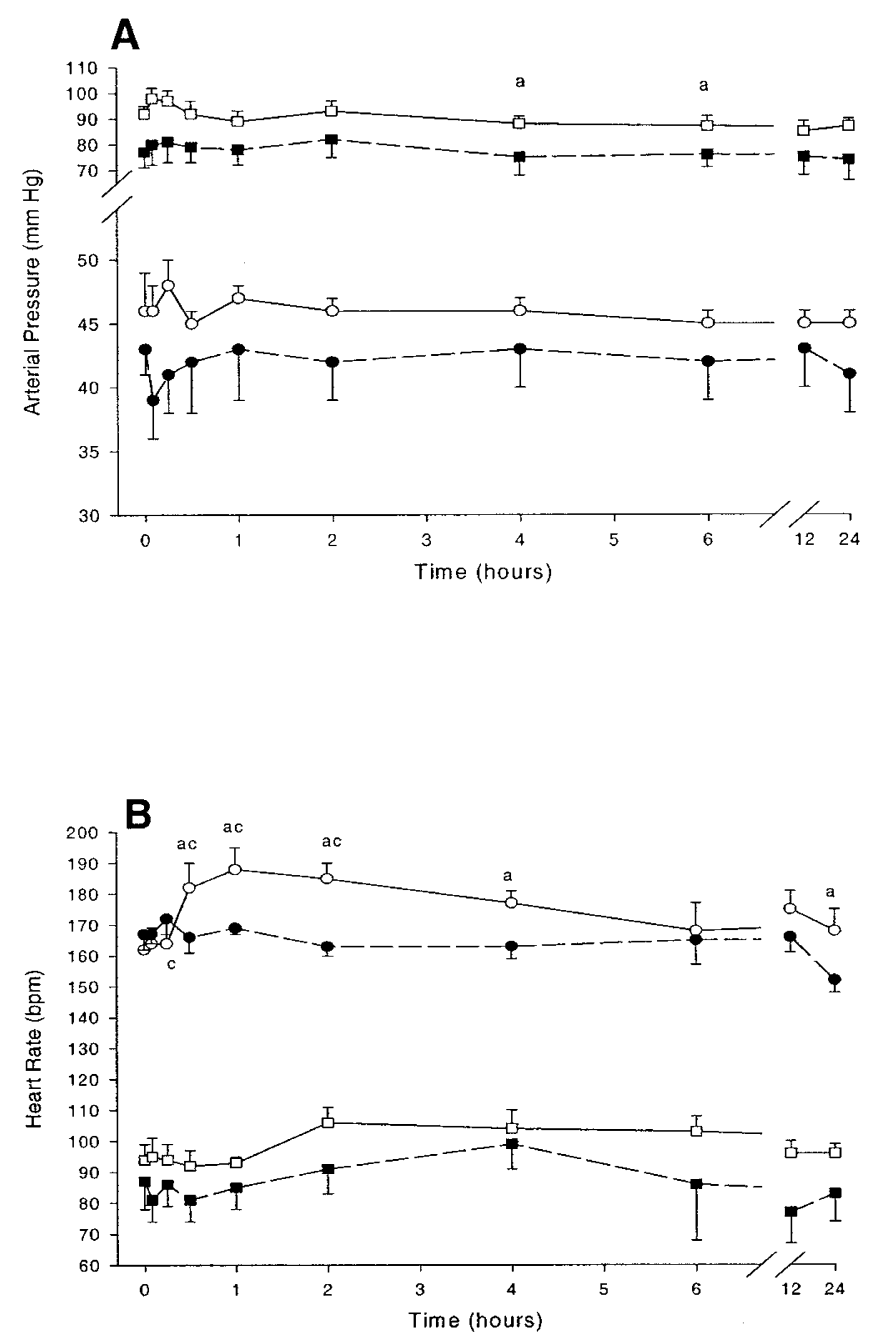

Figure 6. Maternal (squares) and fetal (circles) arterial pressure $(A)$ and heart rate $(B)$ during the first $24 \mathrm{~h}$ of maternal i.v. infusion of vehicle (closed symbols, $n=8$ and 10 for maternal and fetal arterial pressure, $n=6$ and 9 for maternal and fetal heart rate) or FX (open symbols, $n=12$ and 12 for maternal and fetal arterial pressure, $n=7$ and 8 for maternal and fetal heart rate). (a) Significant difference between control and FX groups; significant difference $(p$ $<0.05)$ from preinfusion day in FX group $(c)$.

over this 8-d period (data not shown). Fetal $\mathrm{pH}$ decreased on infusion $\mathrm{d} 1,3,6$, and 7 in the FX group compared with the preinfusion day with the greatest decrease of $-0.026 \pm 0.005$ on infusion d 6 (Table 2). Fetal $\mathrm{Po}_{2}$ also decreased in FX on infusion $\mathrm{d} 2,6$, and 7 compared with the preinfusion day. The maximum decrease in $\mathrm{Po}_{2}$ of $-2.9 \pm 0.9 \mathrm{~mm} \mathrm{Hg}$ occurred on infusion d 6. Compared with preinfusion day, fetal lactate increased on infusion $\mathrm{d} 2,5,6,7$, and 8 in FX and on infusion d 3, 4, 5, 7, and 8 in CON. Fetal oxygen saturation decreased on infusion $\mathrm{d} 2,4,6,7$, and 8 in FX and on infusion $\mathrm{d} 4-8$ in CON. The maximum decrease in oxygen saturation was observed on infusion $\mathrm{d} 4$ in FX $(-14.0 \pm 5.2 \%)$ and on infusion d 8 in $\operatorname{CON}(-12.7 \pm 3.8 \%)$.

Daily average maternal arterial pressure and heart rate were not affected by maternal FX infusion nor was fetal arterial pressure (data not shown). Compared with the preinfusion day $(172 \pm 4 \mathrm{bpm})$, there was a decrease in fetal heart rate on infusion d 2-6 (162 \pm 6 and $157 \pm 6 \mathrm{bpm}$, respectively) in FX.
A decrease in fetal heart rate was also observed in CON on infusion d 4-8 (159 \pm 10 and $150 \pm 6 \mathrm{bpm}$, respectively) compared with the preinfusion day (164 $\pm 4 \mathrm{bpm})$. Fetal heart rate was significantly higher in FX compared with CON on the preinfusion day of the experiment as well as on infusion $\mathrm{d} 1,7$, and 8. This is consistent with the data presented in Figure 7 for fetal heart rate measurements at intervals during the first day.

Daily UABF was analyzed for only the first $5 \mathrm{~d}$ of the protocol, as the sample was not large enough in FX-treated animals beyond this time point for statistical analysis. No significant difference was observed in the percent change from the preinfusion day value of UABF in CON or FX (Fig. $7 B$ ).

\section{DISCUSSION}

This study is the first to examine the possible underlying mechanisms involved in the previously reported negative effects of FX exposure during third trimester in humans. Changes in these variables were measured both acutely and during chronic exposure at clinically relevant plasma concentrations. The results of this study show that maternal i.v. infusion of FX decreases UABF transiently, and this is associated with fetal hypoxemia and respiratory acidemia. This transient response lasts about $12 \mathrm{~h}$ with no chronic changes in UABF. Mild alterations of fetal blood gas status were observed throughout the $8 \mathrm{~d}$ of FX infusion. No negative birth outcomes were observed in terms of birth weight, gestational age at delivery, or intrauterine growth restriction in FX-exposed fetuses compared with control fetuses.

The maternal FX and NFX concentrations in the present study are similar to those reported in humans. The mean maternal FX concentrations fall within the adult human therapeutic range for FX, which is $35-415 \mathrm{ng} / \mathrm{mL}$ in depressed patients taking daily $20 \mathrm{mg}$ doses of the drug (15). In the fetus, the FX concentration averaged $58.9 \pm 14.9 \mathrm{ng} / \mathrm{mL}$ at the end of the infusion period. Our study of nine pregnant women on FX therapy found umbilical cord vein concentrations of 7.9$89.7 \mathrm{ng} / \mathrm{mL}$ at delivery (16). This is similar to the mean value in the fetal lamb on infusion d 8. After a single oral dose of FX in humans, the peak in plasma drug concentration occurs after 5-8 $\mathrm{h}$, and the elimination half-life is $1-4 \mathrm{~d}$ (17). Due to this long half-life, it takes 1-22 mo to achieve steady-state (18) and over this time the mean daily drug concentration would be increasing progressively, likely with daily fluctuations between the peak and trough plasma drug levels. This is somewhat similar to the plasma drug concentration versus time curves resulting from the i.v. administration regimen in the current study, although clearly the initial peak in drug concentration occurs later with oral dosing.

The initial decrease in UABF during the first $30 \mathrm{~min}$ of FX infusion is temporally related to the decrease in fetal arterial $\mathrm{Po}_{2}$. The results are similar to those obtained by Yaffe et al. (19), where a $25 \%$ reduction in UABF, achieved via partial occlusion of the uterine artery, decreased fetal arterial $\mathrm{Po}_{2}$ by approximately $5 \mathrm{~mm} \mathrm{Hg}$. Thus, it is most likely that the fall in $\mathrm{PO}_{2}$ (and rise in $\mathrm{P}_{\mathrm{CO}_{2}}$ ) observed during the first day of $\mathrm{FX}$ infusion are due to decreased UABF. Although it is possible that the drug also affected umbilical blood flow, this seems 
Table 2. Fetal arterial blood gas status at $0700 \mathrm{~h}$ on each day of an 8-d maternal sterile water or FX i.v. infusion expressed as change

\begin{tabular}{|c|c|c|c|c|c|c|c|c|c|c|}
\hline & & Preinf & Inf 1 & Inf 2 & Inf 3 & Inf 4 & Inf 5 & Inf 6 & $\operatorname{Inf} 7$ & $\operatorname{Inf} 8$ \\
\hline \multicolumn{11}{|l|}{$\mathrm{pH}$} \\
\hline Con & Mean & 7.343 & -0.013 & -0.002 & -0.016 & -0.014 & -0.007 & -0.015 & -0.012 & -0.012 \\
\hline \multirow[t]{2}{*}{ FX } & Mean & 7.346 & $-0.017^{\mathrm{c}}$ & -0.011 & $-0.019^{c}$ & -0.013 & -0.009 & $-0.026^{\mathrm{c}}$ & $-0.021^{\mathrm{c}}$ & -0.011 \\
\hline & SEM & 0.007 & 0.008 & 0.007 & 0.007 & 0.004 & 0.005 & 0.005 & 0.007 & 0.009 \\
\hline \multicolumn{11}{|l|}{$\mathrm{Po}_{2}(\mathrm{~mm} \mathrm{Hg})$} \\
\hline \multirow[t]{2}{*}{ FX } & Mean & 23.4 & -0.1 & $-2.4^{\mathrm{c}}$ & -1.1 & -1.9 & -1.6 & $-2.9^{c}$ & $-1.9^{c}$ & -1.5 \\
\hline & SEM & 0.7 & 0.6 & 0.9 & 0.8 & 0.6 & 0.7 & 0.9 & 0.8 & 1.0 \\
\hline \multicolumn{11}{|l|}{$\mathrm{O}_{2}$ Sat. (\%) } \\
\hline \multirow[t]{2}{*}{ Con } & Mean & 56.7 & -1.8 & -2.7 & -4.1 & $-6.8^{\mathrm{b}}$ & $-7.0^{\mathrm{b}}$ & $-7.7^{\mathrm{b}}$ & $-8.5^{\mathrm{b}}$ & $-12.7^{\mathrm{b}}$ \\
\hline & SEM & 2.9 & 1.7 & 2.0 & 2.1 & 2.8 & 2.8 & 2.3 & 4.0 & 3.8 \\
\hline FX & Mean & 61.6 & -1.2 & $-11.1^{\mathrm{c}}$ & -6.9 & $-14.0^{\mathrm{c}}$ & -6.7 & $-8.4^{\mathrm{c}}$ & $-11.0^{\mathrm{c}}$ & $-13.0^{\mathrm{c}}$ \\
\hline \multirow[t]{2}{*}{ FX } & Mean & 0.54 & 0.11 & $0.13^{\mathrm{c}}$ & 0.08 & 0.13 & $0.14^{\mathrm{c}}$ & $0.13^{\mathrm{c}}$ & $0.13^{\mathrm{c}}$ & $0.14^{\mathrm{c}}$ \\
\hline & SEM & 0.07 & 0.06 & 0.07 & 0.05 & 0.05 & 0.06 & 0.08 & 0.09 & 0.08 \\
\hline Con (no.) & & 15 & 15 & 15 & 15 & 14 & 14 & 13 & 10 & 10 \\
\hline FX (no.) & & 12 & 12 & 12 & 12 & 11 & 11 & 11 & 8 & 7 \\
\hline
\end{tabular}

Note that preinfusion and infusion $\mathrm{d} 1$ are preinfusion values.

Preinf, preinfusion day; Inf, infusion day; $\mathrm{O}_{2}$ Sat., oxygen saturation.

${ }^{\mathrm{a}}$ Significant difference between control and FX groups $(p<0.05)$; significant difference $(p<0.05)$ from preinfusion day in ${ }^{\mathrm{b}}$ control and ${ }^{\mathrm{c}} \mathrm{FX}$ group.

unlikely. With experimental reductions in umbilical blood flow, there is fetal hypertension and bradycardia (20), whereas in the FX-exposed fetuses, there was no change in arterial pressure and tachycardia during the period of hypoxemia.

As noted in the "Introduction," serotonin is a uterine vasoconstrictor. Thus, we believe that the FX-elicited fall in uterine blood flow is caused by a rise in plasma serotonin levels, due to drug-induced inhibition of serotonin uptake by platelets. Plasma serotonin concentrations increase immediately after FX injection in humans and rats (21) and we have observed a similar effect on maternal plasma serotonin concentration after a $70 \mathrm{~g}$ i.v. bolus dose of FX in two pregnant ewes (Morrison JL, Chien C, Gruber N, Riggs W, de la Presa Owens S, Innis $\mathrm{S}$, Rurak $\mathrm{D}$, unpublished data). In an acute study, a 1- $\mu \mathrm{g}$ injection of serotonin directly into the uterine vasculature reduced UABF by approximately $20 \%$ (12).

Fetal $\mathrm{PCO}_{2}$ increased in the FX-exposed fetuses during the first $12 \mathrm{~h}$ of maternal FX infusion. In studies involving experimental reduction of $\mathrm{UABF}$, a tendency toward an increase in $\mathrm{PCO}_{2}$ has been observed (19). In addition, significant increases in fetal $\mathrm{PCO}_{2}$ occur with spontaneous uterine contractures, which reduce uterine blood flow (22). Inasmuch as we did not observe any changes in base excess in FX, the decrease in $\mathrm{pH}$ observed in $\mathrm{FX}$ is due to the rise in $\mathrm{PCO}_{2}$. Maternal and fetal glucose concentrations rose at $4 \mathrm{~h}$ postinfusion in both CON and FX due to feeding between the 1 and $2 \mathrm{~h}$ samples. The increases in lactate at these time points are likely due to the increase in glucose (23), but the significant rise in fetal lactate concentration in the FX group after FX infusion is consistent with the decrease in $\mathrm{Po}_{2}$ (24). The main cardiovascular effect observed was the increase in fetal heart rate during the first $6 \mathrm{~h}$ of FX infusion. Comparison of Figures 6 and 7 show that the time course for the tachycardia is similar to the time course for the lactic acidemia. Experimental lactic acidemia, similar to that observed with acute reductions in UABF, result in increased fetal $\mathrm{PCO}_{2}$ and sustained tachycardia (25).

Chronic FX exposure caused only minor alterations of fetal blood gas status. It should be noted that fetal $\mathrm{Po}_{2}$ (although not significant in $\mathrm{CON}$ ) and oxygen saturation decreased throughout the 8-d infusion period in both CON and FX, although the magnitude of the fall was greater in FX. Over this time period, $\mathrm{UABF}$ in $\mathrm{FX}$ and $\mathrm{CON}$ were not different, and in neither group did it fall. Thus, the reduced fetal oxygenation over this time period was not due to reduced UABF. The lack of change in the FX animals is consistent with the reported effects of chronic FX treatment on serotonin levels in other species. Although acute FX treatment increases plasma serotonin concentration, chronic FX treatment causes a decrease in plasma and platelet serotonin levels in humans and mice $(26,27)$. Weight-normalized umbilical blood flow decreases progressively in late gestation in the sheep (28), and this may be associated with a progressive fall in vascular $\mathrm{Po}_{2}$ (29). This would explain the fall in fetal oxygenation during the infusion period observed in both CON and FX. The decrease in fetal heart rate in both CON and FX over the $8 \mathrm{~d}$ of infusion is consistent with previous findings of a fall in heart rate with increasing gestational age $(30,31)$.

Thus, the major effects of FX on the fetus in the current study occurred on the first day consisting of transient hypoxemia, respiratory acidemia, hyperlactic acidemia, and tachycardia of approximately $6 \mathrm{~h}$ duration. Changes of this duration and magnitude would not be expected to affect either gestational length or fetal growth. This is consistent with the lack of differences in gestational length and birth weight in the CON 

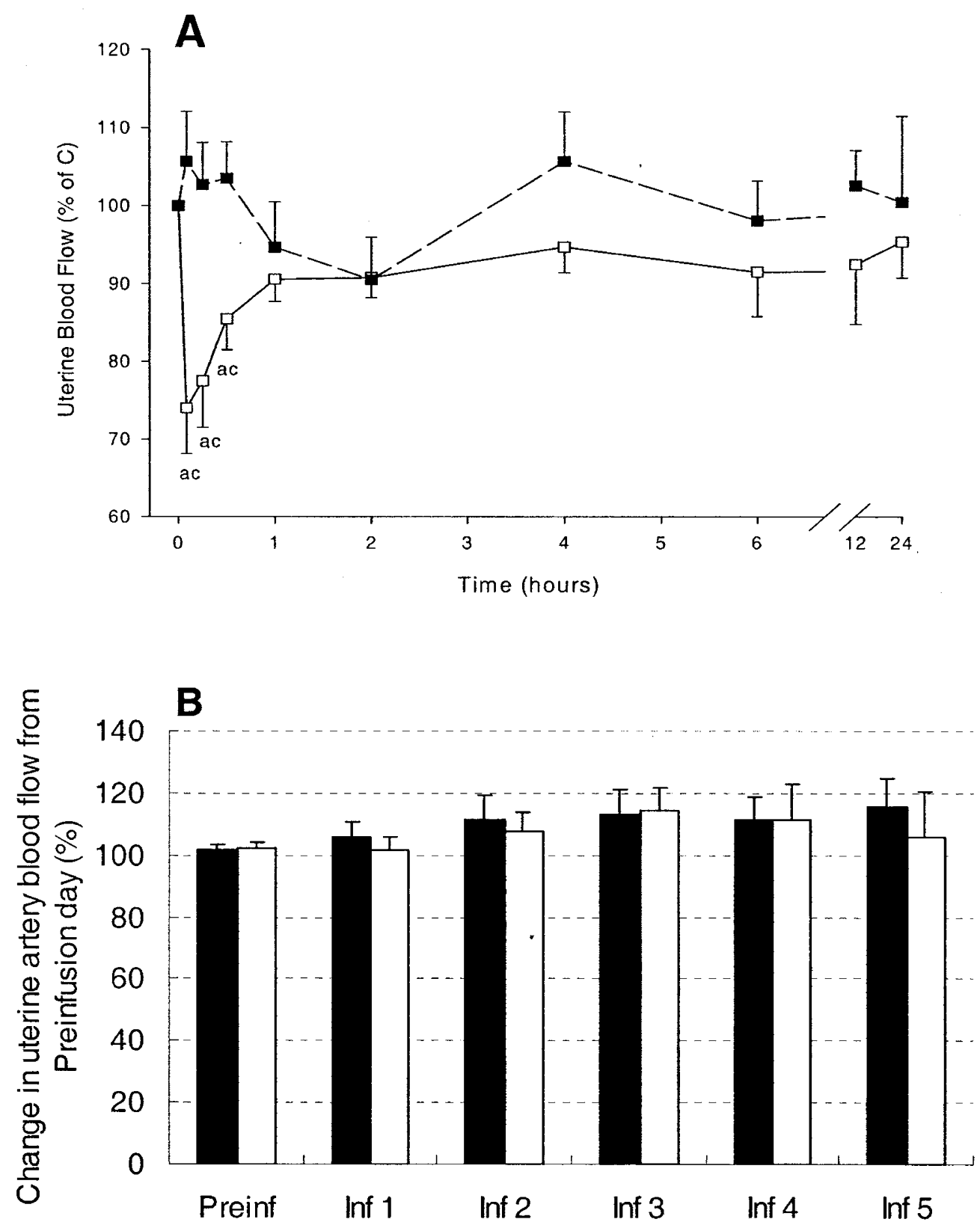

Figure 7. Percent change in uterine artery blood flow from preinfusion day in sterile water (closed squares/bars, $n=5$ ) or FX (open squares/bars, $n=6)$ treated groups during the first $24 \mathrm{~h}$ after infusion began $(A)$ and during the first $5 \mathrm{~d}$ of the 8 -d infusion period $(B)$. The $n$ value for the FX group decreased to 5 on infusion

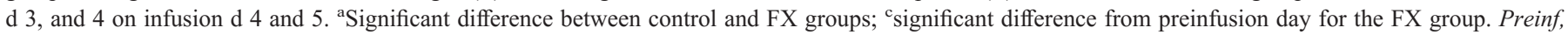
preinfusion day; Inf, infusion day.

and FX groups. Thus, the results are not consistent with studies by Chambers et al. (6) and Goldstein (7) that found an increase in preterm delivery and lower birth weight in fetuses exposed to FX during the third trimester. It is possible that the severity of the underlying depression requiring pharmacological treatment into the third trimester may have resulted in the adverse outcomes in these studies. Differences in lifestyle such as increased smoking and alcohol consumption rather than a direct pharmacological effect of FX may also have also been responsible (7). Alternatively, it is possible that exposure to FX throughout most or all of pregnancy may be required to result in preterm delivery or reduced birth weight.
Although there was no apparent differences in intrauterine growth between the two groups, postnatal growth in the FXexposed lambs was significantly lower than in the CON animals on $\mathrm{d} 2$ with a rebound on $\mathrm{d} 5$. The transient slowing of growth in the FX group may reflect the poor neonatal adaptation that has been reported in human infants exposed to FX in the third trimester by Chambers et al. (6), and more recently by Cohen et al. (32). This comprises several features including jitteriness, respiratory difficulties, hypoglycemia, lethargy, and poor tone, some of which could impair sucking behavior. Such behavior could result from altered brain development due to in utero exposure to FX, or from pharmacologic effects of the 
drug still present in the infants in the early postnatal period. In both the fetal lamb and human, there is no evidence for an ability to metabolize FX, and in human infants at the time of phenylketonuria testing (i.e. at $2 \mathrm{~d}$ following birth), the plasma FX concentration is the same as in cord blood at delivery (16). A similar situation in the FX exposed lambs could have impaired feeding behavior and resulted in the transient slowing of growth. Although we did not notice any abnormal behavioral features in these animals, a systematic examination was not conducted. In the human studies $(6,32)$, postnatal weight gain was not reported. It may be clinically relevant for future human studies to include postnatal growth estimates.

The FX-elicited transient changes in fetal $\mathrm{PO}_{2}$ and $\mathrm{PCO}_{2}$ are similar in magnitude to those occurring with contractures and fetal skeletal muscle activity, which are normal features of fetal life (22). However, these physiologic events last only several minutes, whereas the FX-induced decrease in UABF was significant for 30 min whereas $\mathrm{Po}_{2}$ decreased for $24 \mathrm{~h}$. In addition, pulsatile administration of oxytocin to pregnant ewes from $96 \mathrm{~d}$ gestation until term to increase the frequency of contractures and hence the episodes of fetal hypoxemia is associated with accelerated cardiovascular and neurologic maturation $(33,34)$. As noted earlier, daily oral FX dosing in humans likely results in daily fluctuations in plasma FX levels, i.e. a peak in concentration followed by a trough. If this leads to daily FX-induced decreases in UABF and fetal vascular $\mathrm{PO}_{2}$ of the magnitude and duration that occurred on the first day of drug infusion in the current study, there could be impacts on fetal growth and development.

In summary, the primary effects of maternal 8-d i.v FX infusion were a transient reduction in UABF and fetal oxygenation over approximately 1 and approximately $24 \mathrm{~h}$, respectively, on the first infusion day, with no significant antenatal changes thereafter. However, postnatal weight gain was transiently decreased in the FX-exposed lambs. Further studies are warranted to extend our observations, particularly to determine whether the maternal plasma FX concentration profile associated with a daily oral dosing regimen results in a daily decrease in UABF and fetal hypoxemia. In addition, more information on postnatal behavior and weight gain in infants exposed to FX in utero would be very useful. Such data are necessary to fully assess the safety of FX and similar drugs in pregnancy.

Acknowledgments. The authors thank Novopharm (Toronto, ON, Canada) for the generous donation of fluoxetine hydrochloride.

\section{REFERENCES}

1. Weissman MM, Olfson M 1995 Depression in women: implications for health care research. Science 269:799-801

2. Lawrenson RA, Tyrer F, Newson RB, Farmer RDT 2000 The treatment of depression in UK general practice: selective serotonin reuptake inhibitors and tricyclic antidepressants compared. J Affect Disord 59:149-157

3. Misri S, Kostaras D, Kostaras X 2000 The use of selective serotonin reuptake inhibitors during pregnancy and lactation: current knowledge. Can J Psychiatry 45:285-287

4. Pastuszak A, Schick-Boschetto B, Zuber C, FM, Pinelli M, Sihn S, Donnenfeld A, McCormack M, Leen-Mitchell M, Woodland C, Gardner A, Hom M, Koren G 1993 Pregnancy outcome following first-trimester exposure to fluoxetine (Prozac). JAMA 269:2246-2248
5. Addis A, Koren G 2000 Safety of fluoxetine during the first trimester of pregnancy: a meta-analytical review of epidemiological studies. Psychol Med 30:89-94

6. Chambers CD, Johnson KA, Dick LM, Felix RJ, Jones KL 1996 Birth outcomes in pregnant women taking FX. N Engl J Med 335:1010-1015

7. Goldstein DJ 1995 Effects of third trimester fluoxetine exposure on the newborn. J Clin Psychopharmacol 15:417-420

8. Nulman I, Rovet J, Stewart D, Wopin J, Gardner HA, Theis JGW, Kulin N, Koren G 1997 Neurodevelopment of children exposed in utero to antidepressant drugs. N Engl J Med 336:258-262

9. Blier P, de Montigny C 1998 Possible serotonergic mechanisms underlying the antidepressant and anti-obsessive-compulsive disorder responses. Biol Psychiatry 44:313-323

10. Karlsson C, Bodelsson G, Bodelsson M, Stjernquist M 1999 Characterisation of 5-hydroxytryptamin receptors mediating circular smooth muscle contraction in the human umbilical artery. Gynecol Obstet Invest 47:102-107

11. Berman W, Goodlin RC, Heyman MA, Rudolph AM 1978 Effects of pharmacologic agents on umbilical blood flow in fetal lambs in utero. Biol Neonate 33:225-235

12. Clark KE, Mills EG, Otte TE, Stys SJ 1980 Effect of serotonin on UABF in pregnant and nonpregnant sheep. Life Sci 27:2655-2661

13. Rurak DW, Yoo SD, Kwan E, Taylor SM, Riggs KW, Axelson JE 1988 Effects of diphenhydramine in the fetal lamb after maternal or fetal administration. J Pharmacol Exp Ther 247:271-278

14. Kim J, Axelson JE, Kearns GL, Yin W, Rurak DW 1995 Stereoselective determination of fluoxetine and norfluoxetine with mass-selective detection (GC/MSD). Pharm Res 12:s22

15. Benfield P, Heel RC, Lewis SP 1986 Fluoxetine: a review of its pharmacodynamic and pharmacokinetic properties, and therapeutic efficacy in depressive illness. Drugs 32:481-508

16. Kim J, Misri S, Kent N, Oberlander T, Rurak DW, Riggs KW 1999 Comparison of fetal and neonatal fluoxetine and paroxetine exposure during the perinatal period in humans. AAPS PharmSci 1:S96

17. Lemberger L, Bergstrom RF, Wolen RL, Farid NA, Enas GG, Aronoff GR 1985 Fluoxetine: clinical pharmacology and physiologic disposition. J Clin Psychiatry 46:14-19

18. Hiemke C, Härtter S 2000 Pharmacokinetics of selective serotonin reuptake inhibitors. Pharmacol Ther 85:11-28

19. Yaffe H, Parer JT, Block BS, Llanos AJ 1987 Cardiorespiratory responses to graded reductions of UABF in the sheep fetus. J Dev Physiol 9:325-336

20. Giussani DA, Unno N, Jenkins SL, Wentworth RA, Derks JB, Collins JH, Nathanielsz PW 1997 Dynamics of cardiovascular responses to repeated partial umbilical cord compression in late-gestation sheep fetus. Am J Physiol 273:H2351-H2360

21. Ortiz J, Artigas F 1992 Effects of monoamine uptake inhibitors on extracellular and platelet 5-hydroxytryptamine in rat blood: different effects of clomipramine and fluoxetine. J Pharmacol 105:941-946

22. Llanos AJ, Court DJ, Block BS, Germain AM, Parer JT 1986 Fetal cardiorespiratory changes during spontaneous prelabor uterine contraction in sheep. Am J Obstet Gynecol 155:893-897

23. Slater JS, Mellor DJ 1981 Within-day variations in the composition of maternal and fetal plasma from catheterised ewes fed once daily or at hourly intervals during late pregnancy. Res Vet Sci 31:224-230

24. Towell ME, Figueroa J, Markowitz S, Elias B, Nathanielsz P 1987 The effect of mild hypoxemia maintained for twenty-four hours on maternal and fetal glucose, lactate, cortisol, and arginine vasopressin in pregnant sheep at 122 to 139 days' gestation. Am J Obstet Gynecol 157:1550-1557

25. Bocking AD, Challis JRG, White SE 1991 Effect of acutely-induced lactic acidemia on fetal breathing movements, heart rate, blood pressure, ACTH and cortisol in sheep. J Dev Physiol 16:45-50

26. Alvarez JC, Gluck N, Arnulf I, Quintin P, Leboyer M, Pexquery R, Launay JM, Perez-Diaz F, Spreux-Varoquaux O 1999 Decreased platelet serotonin transporter sites and increased platelet inositol triphosphate levels in patients with unipolar depression: effects of clomipramine and fluoxetine. Clin Pharmacol Ther 66:617-624

27. Alvarez JC, Sanceaume M, Advenir C, Spreux-Varoquaux O 1999 Differential changes in brain and platelet 5-HT concentrations after steady-state achievement and repeated administration of antidepressant drugs in mice. Eur Neuropsychopharmacol $10: 31-36$

28. Hedriana HL, Brace RA, Gilbert WM 1995 Changes in blood flow to the ovine chorion and amnion across gestation. J Soc Gynecol Investig 2:727-734

29. Bell AW, Kennaugh JM, Battaglia FC, Makowski EL 1986 Metabolic and circulatory studies of fetal lambs at midgestation. Am J Physiol 250:E538-E544

30. Boddy K, Dawes GS, Fisher R, Pinter S, Robinson JS 1974 Foetal respiratory movements, electrocortical and cardiovascular responses to hypoxaemia and hypercapnia in sheep. J Physiol 243:599-618

31. Tan W 1997 Circulatory and metabolic studies of normally grown and growth restricted fetal sheep before and during spontaneous labor and delivery. PhD thesis, University of British Columbia, Vancouver, British Columbia, Canada, pp 154-160

32. Cohen LS, Heller VL, Bailey JW, Grush L, Ablon JS, Bouffard SM 2000 Birth outcomes following perinatal exposure to fluoxetine. Biol Psychiatry 48:996-1000

33. Shinozuka N, Nathanielsz PW 2000 Increased myometrial contracture frequency at 96 to 140 days gestation (dGA) accelerates high voltage (HV)/low voltage (LV) electrocorticgram cyclicity maturation in fetal sheep. J Soc Gynecol Investig 7:108A

34. Shinozuka N, Yen A, Nathanielsz PW 2081999 Alteration of fetal oxygenation and responses to acute hypoxemia by increased myometrial contracture frequency produced by pulse administration of oxytocin to the pregnant ewe from 96-131 days' gestation. Am J Obstet Gynecol 180:1202-1 